\title{
Selection of Thermotolerant Corynebacterium glutamicum Strains for Organic Acid Biosynthesis
}

\section{Martyna Leszczewicz ${ }^{1,2 *}$ (1) and Piotr Walczak ${ }^{2}$ \\ 'Industrial Biotechnology Laboratory, "Bionanopark" Ltd., Dubois 114/116, 93-465 Łódź, Poland \\ Institute of Fermentation Technology and Microbiology, Lodz University of Technology, Wólczańska 171/173, 90-924 Łódź, Poland}

Received: 7 August 2018 Accepted: 2 May 2019

\section{(i) ()}

*Corresponding author:

Phone: +48422807676

Fax: +48426845000

E-mail:mleszczewicz@gmail.com

\section{SUMMARY}

In recent years, Corynebacterium glutamicum has been considered as producer of many valuable chemical compounds. Among them, organic acids such as L-lactic and succinic acids are the most important ones. It is known that the wild-type C. glutamicum grows well in the temperature range between 25 and $37^{\circ} \mathrm{C}$. Above $40^{\circ} \mathrm{C}$, the biomass growth usually abruptly stops; however, the bacteria remain metabolically active. High temperature affects the metabolic activity of $C$. glutamicum cells and can lead to changes in the composition and quantity of the fermentation products. Therefore, in a series of subsequent selection steps, we tried to obtain prototrophic strains capable of growing at $44^{\circ} \mathrm{C}$ from the culture of homoserine auxotroph C. glutamicum ATCC 13287. During selection, we used complex and mineral media containing succinic and citric acids. As a result, we obtained 47 clones able to grow at elevated temperature. Moreover, the estimated optimal growth temperature for several of them was about $40^{\circ} \mathrm{C}$ or higher. Under oxygen limitation conditions, $C$. glutamicum strains produce organic acids. Regardless of the tested clone, L-lactic acid was the main product. However, its concentration was the highest in the cultures performed at $44{ }^{\circ} \mathrm{C}$. The elevated temperature also affected the biosynthesis of other organic acids. Compared to the parental strain, the concentration of acetic acid increased, and of succinic acid decreased in the cultures of thermotolerant strains. Strain RCG44.3 exhibited interesting properties; it was able to synthesise $27.1 \mathrm{~g} / \mathrm{L}$ L-lactic acid, with production yield of 0.57 $\mathrm{g} / \mathrm{g}$, during $24 \mathrm{~h}$ of fermentation at $44^{\circ} \mathrm{C}$.

Key words: thermotolerant Corynebacterium glutamicum, L-lactate, succinate, acetate

\section{INTRODUCTION}

Corynebacterium glutamicum was isolated in 1956 in Japan as a producer of glutamic acid (1). Shortly after that, various strains of C. glutamicum have been developed for the biosynthesis of other amino acids, such as L-lysine, L-methionine and L-threonine (2). In recent years, C. glutamicum has also been considered as a producer of many other valuable chemical compounds. Among them, lactic, succinic, $\gamma$-aminobutyric and 5 -aminolevulinic acids, ethanol, isobutanol and xylitol, cadaverine and putrescine, and polymers, such as polyhydroxybutyrate have the highest application potentials (3-14).

Lactic acid is an essential chemical compound broadly applied in food, pharmaceutical, cosmetic and agricultural industries. It is also a precursor for the synthesis of 1,2-propanediol, acrylic acid and polylactic acid (15). The latest trends in the use of biodegradable materials manufactured from renewable resources include the production of packaging materials, various household and office articles, as well as modern fabrics, products for agriculture and even medical implants, resulting in increased demand for this feedstock. Chemical synthesis of lactic acid results in the production of a racemic mixture of this compound, whereas production of polylactic acid requires optically pure stereoisomers of Lor D-lactic acid since physical properties of the manufactured polymer strongly depend on the ratio of stereoisomers used in its formation. Therefore, biotechnological methods give an opportunity to produce optically pure substrates for polylactic acid manufacturing (16). However, only certain microorganisms are capable of synthesising solely one lactic 
acid stereoisomer. C. glutamicum has such exceptional property. Its genome contains only one L-lactate dehydrogenase gene, and therefore it is possible to obtain pure L-lactic acid in the fermentation process carried out by this microorganism $(3,17,18)$. On the other hand, genetically engineered strains of C. glutamicum, obtained by knockout of L-lactate dehydrogenase gene and expression of D-lactate dehydrogenase gene from Lactobacillus delbrueckii ssp. bulgaricus or Escherichia coli, can also produce D-lactic acid $(4,19)$.

Temperature, widely discussed in this manuscript, is a crucial factor in many biotechnological processes since it affects the solubility of medium components, the rate of chemical reactions and metabolism of microbial cells. The majority of $C$. glutamicum strains grow well in the temperature range between 25 and $37{ }^{\circ} \mathrm{C}$. Above $40^{\circ} \mathrm{C}$, their growth is abruptly stopped (20). Ohnishi et al. (21) described the influence of temperature on the central metabolism, amino acid biosynthetic pathways, and selected transport systems in C. glutamicum. It may be expected that the temperature rise considerably above the optimum will cause inhibition of the majority of metabolic reactions.

Nonetheless, the transcriptome analysis showed that the expression of certain enzymes increases at the temperature above $40^{\circ} \mathrm{C}$. Furthermore, several of them are involved in the central metabolism, particularly in phosphotransferase transport system - ptsH and ptsM, pentose phosphate pathway 6-phosphogluconolactonase ( $p g l)$, glycolysis - phosphoglycerate mutase ( $\mathrm{gpm}$ ) and phosphoenolpyruvate synthase (pps), tricarboxylic acid cycle (TCA) - aconitase (can), succinyl-CoA synthetase (sucC), succinate:menaquinone oxidoreductase $(s d h A, s d h C)$ and malate dehydrogenase ( $m d h)$, as well as gluconeogenic genes encoded by malic enzyme (malE) and phosphoenolpyruvate carboxykinase ( $p c k$ ). Down-regulation is evident only in a few cases. The most important are glyceraldehyde-3-phosphate dehydrogenase (gapA), citrate synthase $(g / t A)$, isocitrate lyase $(a c e A)$ and malate synthase $(a c a B)$, which participate respectively in glycolysis, TCA cycle and glyoxylate shunt (21). One of the consequences of the metabolic deregulation is the decrease in the biomass concentration (22-25). Owning to the fact that quick temperature increase to about $40{ }^{\circ} \mathrm{C}$ causes an abrupt increase in the glutamate specific production rate, the cultivation at a higher temperature may be very applicable in its commercial production. The metabolic activity of C. glutamicum 2262 did not increase. However, the excretion of glutamate was more efficient. Further temperature rise had quite the opposite effect. At $41^{\circ} \mathrm{C}$, a dramatic reduction in the biomass growth rate and glutamate concentration was observable. Cultivation at the elevated temperature caused an increase in the formation of lactic acid (22). Accumulation of pyruvate is another striking consequence of metabolism disturbance and may denote the bottleneck. Although it is an essential central metabolite, its high concentration is detrimental to the bacteria. The cell defence strategy is to detoxify pyruvate by its transformation to lactic acid and excretion $(23,26)$. Therefore, this phenomenon can have a significant impact on the production of lactic acid by C. glutamicum.

Due to the availability of genomes of several C. glutamicum strains, and manifold sophisticated molecular biology methods, it is possible to introduce changes in gene sequences, leading to the reduction of susceptibility to the elevated temperature $(27,28)$. One of the most promising is genome shuffling, which mimics natural evolution. Zheng et al. (29) used this method to improve thermotolerance of glutamic acid-producing strains C. glutamicum S9114 and ATCC 13761. Strain F343 was obtained after three rounds of mutagenesis and gene shuffling. It was stable at least for ten generations, able to grow at $44{ }^{\circ} \mathrm{C}$ and produced more L-glutamic acid than its ancestors. Another essential tool for strain improvement is adaptive laboratory evolution (ALE), based on the same mechanisms as Darwinian evolution (30). If bacterial cells are exposed to harmful or stressful conditions, such as high temperature, the mutations that allow for survival are accumulated. In the case of bacteria, it is easy to imitate the long-term influence of noxious environment, because within a few weeks, several hundred generations may be treated with one, clearly defined factor. As a consequence, new strain adapted to the environmental conditions, exhibiting specific phenotypic changes, may be obtained (31). Therefore, over the past few decades, ALE has been used multiple times for $C$. glutamicum improvement. The reports that have already been published pertain mainly to the selection for growth during environmental stress, including high temperature $(31,32)$.

All these methods have certain drawbacks. They are expensive or time-consuming. Granted that among the population of microorganisms it is possible to find single cells exhibiting improved properties, which are provoked by former mutagenization or are the result of the accumulation of spontaneous mutations, we propose another approach to the improvement of strain properties.

\section{MATERIALS AND METHODS}

\section{Bacterial strains and growth conditions}

Corynebacterium glutamicum ATCC 13287 was obtained from LOCK 105 collection (Lodz, Poland). This microorganism is an auxotrophic mutant unable to synthesise homoserine (33). Other strains were selected from the culture of the parental strain. Bacterial cultures were kept frozen at $-20^{\circ} \mathrm{C}$ in glycerol stocks. Before use, they were activated overnight on complex medium consisting of (in $\mathrm{g} / \mathrm{L}$ ): beef extract 10, bactopeptone 10, yeast extract 5 and agar 10 (all from BTL, Lodz, Poland), and $\mathrm{NaCl} 3$ (Chempur, Piekary Slaskie, Poland), at 30 or $44{ }^{\circ} \mathrm{C}$ depending on the strain requirement. Biomass was propagated in the complex medium containing (in $\mathrm{g} / \mathrm{L}$ ): beef extract 10, bactopeptone 10 and yeast extract 5 (all from $\mathrm{BTL}$ ), and $\mathrm{NaCl} 3$ (Chempur), during $18 \mathrm{~h}$ in a shake flask culture at $180 \mathrm{rpm}$ and 30 or $44^{\circ} \mathrm{C}$. We evaluated the bacterial growth and carbon source consumption of activated strains, which were first cultured for $18 \mathrm{~h}$ at 30 or $44^{\circ} \mathrm{C}$ in shake flasks 
(180 rpm) containing medium A composed of (in g/L): glucose 20, $\left(\mathrm{NH}_{4}\right)_{2} \mathrm{SO}_{4} 6.6, \mathrm{KH}_{2} \mathrm{PO}_{4} 1, \mathrm{MgSO}_{4} \cdot 7 \mathrm{H}_{2} \mathrm{O} 0.2, \mathrm{FeSO}_{4} \cdot 7 \mathrm{H}_{2} \mathrm{O}$ 0.01 and $\mathrm{CaCl}_{2} 0.01$ (all from Chempur), casein hydrolysate 10

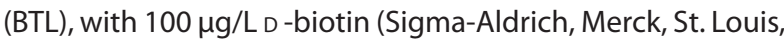
$\mathrm{MO}, \mathrm{USA}$ ) and if necessary $500 \mu \mathrm{g} / \mathrm{L}$ thiamine (Sigma-Aldrich, Merck). Then, the proliferated cells were transferred to medium B containing (in g/L): glucose 100, $\left(\mathrm{NH}_{4}\right)_{2} \mathrm{SO}_{4} 6.6, \mathrm{KH}_{2} \mathrm{PO}_{4}$ $1, \mathrm{MgSO}_{4} 7 \mathrm{H}_{2} \mathrm{O} 0.2, \mathrm{FeSO}_{4} \cdot 7 \mathrm{H}_{2} \mathrm{O} 0.01$ and $\mathrm{CaCl}_{2} 0.01$ (all from Chempur), with $100 \mu \mathrm{g} / \mathrm{L} \mathrm{D}$-biotin and if necessary $500 \mu \mathrm{g} / \mathrm{L}$ thiamine (both from Sigma-Aldrich, Merck), and cultured under the same conditions.

\section{Selection of revertants}

Previously activated ATCC 13287 strain was proliferated overnight in shake flask culture at $180 \mathrm{rpm}$ and $30^{\circ} \mathrm{C}$ on complex medium adjusting the absorbance to $A_{540 \mathrm{~nm}}=2.2$ (concentration about $6 \mathrm{~g} / \mathrm{L}$ ). After that, the biomass was centrifuged (model MPW-365; JW Electronic, Warsaw, Poland) at 7000 $\times 9$ and $4{ }^{\circ} \mathrm{C}$ for $4 \mathrm{~min}$ and washed twice with $0.85 \%$ saline solution, then plated on medium A without homoserine, and solidified by the addition of $2 \mathrm{~g} / \mathrm{L}$ agar (BTL). After $48 \mathrm{~h}$ of incubation at $30^{\circ} \mathrm{C}$, single colonies were isolated. The growth rate of each clone was measured as described previously.

\section{Selection of thermotolerant strains on complex medium}

Selected revertants and the reference strain C. glutamicum ATCC 13287 were activated and proliferated in complex medium at $30^{\circ} \mathrm{C}$. Thick suspensions of the bacterial cells with $A_{540 \mathrm{~nm}}=5$ (concentration about $13.5 \mathrm{~g} / \mathrm{L}$ ) were seeded on solidified complex agar and incubated for $24 \mathrm{~h}$ at $44^{\circ} \mathrm{C}$. All visible colonies were isolated and their growth and carbon source consumption were compared.

\section{Selection of thermotolerant strains on mineral media}

The variants of the strain selected in the previous step were activated and then propagated overnight at $44^{\circ} \mathrm{C}$ in medium $A$. Then, bacterial cells were seeded on plates with medium A solidified by the addition of $2 \mathrm{~g} / \mathrm{L}$ agar (BTL, Lodz, Poland), which contained instead of glucose (in $\mathrm{g} / \mathrm{L}$ ): citrate 15 or 10 (Chempur) with glutamic acid 5 (Warchem, Warsaw, Poland), or succinate 15 or 10 (Sigma-Aldrich, Merck) with glutamic acid 5 (Warchem). Positive controls were seeded on the medium A solidified by the addition of $2 \mathrm{~g} / \mathrm{L}$ agar (BTL) and negative controls on the same medium without the addition of carbon source. The cultures were incubated at $44{ }^{\circ} \mathrm{C}$ for 72 h. Then, single colonies were isolated and their growth and glucose consumption were tested.

\section{Determination of optimal growth temperature}

Reference strain C. glutamicum ATCC 13287 and other strains selected at various stages of growth were used. All strains were activated and propagated at $35^{\circ} \mathrm{C}$ in medium A. The biomass was then transferred to medium $B$ and the cultures were cultivated at $20,25,30,35,40,45$ or $50^{\circ} \mathrm{C}$. After $24 \mathrm{~h}$ of incubation, the biomass concentration was measured.

\section{Comparison of organic acid production under oxygen- -limiting conditions by strains isolated at various stages of selection}

The strains used previously for determination of optimal growth temperatures were tested for organic acid production, in particular, lactic, succinic and acetic acids. Strains were activated and cultivated in shake flasks in medium A for $18 \mathrm{~h}$ at $180 \mathrm{rpm}$ and 30 or $44^{\circ} \mathrm{C}$, depending on their requirements. Then, the cells were centrifuged (model MPW-365; JW Electronic) at $7000 \times \mathrm{g}$ and $4{ }^{\circ} \mathrm{C}$ for $4 \mathrm{~min}$, and transferred to medium $B$ with the addition of $45 \mathrm{~g} / \mathrm{L} \mathrm{CaCO}_{3}$ (Chempur), so as the initial biomass concentration in each culture was approx. $10 \mathrm{~g} / \mathrm{L}$. The fermentations were performed for $24 \mathrm{~h}$ in tightly closed shake flasks (at $100 \mathrm{rpm}$ ), filled with the medium up to $2 / 3$ of the total volume, at 30 or $44{ }^{\circ} \mathrm{C}$, depending on the strain requirements.

\section{Determination of biomass concentration}

Samples were collected every $24 \mathrm{~h}$. Cell growth was monitored at $A_{540 \mathrm{~nm}}$ using T60V UV-Vis spectrophotometer (PG Instruments Ltd, Leicestershire, UK). The biomass was calculated according to a standard curve, where $0.1 \mathrm{~g} / \mathrm{L}$ is equivalent to $A_{540 \mathrm{~nm}}=0.272$.

\section{Measurement of the substrate and organic acid concentration}

For the evaluation of lactic, succinic and acetic acids as well as glucose concentration, the samples were centrifuged (model MPW-365; JW Electronic) at $9000 \times g$ and $4{ }^{\circ} \mathrm{C}$ for 10 $\mathrm{min}$, and the supernatants were analyzed with Surveyor Plus HPLC with refractive index (RI) plus detector (Thermo Fisher Scientific, Waltham, MA, USA) on the Aminex HPX-87H column (Bio-Rad, Hercules, CA, USA). Chromatographic separation was carried out with $10 \mu \mathrm{L}$ of the sample at $60^{\circ} \mathrm{C}$ in the presence of $5 \mathrm{mM}$ sulfuric acid (Sigma-Aldrich, Merck) as eluent, and flow velocity was equal to $0.6 \mathrm{~mL} / \mathrm{min}$.

\section{Stereospecificity of lactic acid}

The concentration of $\mathrm{L}$ - and D-lactic acid was determined by the enzymatic method, using D-/L-lactic acid (D-/L-lactate) assay kit (Megazyme, Bray, Wicklow, Ireland). All solutions and necessary standards were prepared in accordance with the manufacturer's instructions. Measurements were performed using T60 UV-Vis spectrophotometer (PG Instruments Ltd).

\section{Statistical analysis}

The calculations, including mean values and standard deviations, were made using Excel Professional 2007 (33). The 
production yield $\left(Y_{\mathrm{PS}}\right)$ and productivity $Q_{\mathrm{p}}$ were determined using the following equations:

and

$$
Y_{\mathrm{PS}}=\frac{\Delta c_{\mathrm{P}}}{\Delta c_{\mathrm{S}}}
$$

$$
Q_{p}=\frac{\Delta c_{p}}{t}
$$

where $\Delta c_{\mathrm{p}}$ and $\Delta c_{\mathrm{s}}$ are the changes in product and substrate concentration respectively, and $t$ is fermentation time.

\section{RESULTS AND DISCUSSION}

\section{Isolation of revertants}

Corynebacterium glutamicum ATCC 13287 is a homoserine dehydrogenase (hom)-deficient mutant derived from its parent prototrophic strain ATCC 13032, which had been subjected to mutagenesis by UV irradiation aimed at blocking the pathway leading to homoserine biosynthesis. As a result, the strain was incapable of the biosynthesis of L-homoserine and proteinogenic amino acids, i.e. L-methionine and L-threonine, and other substances whose precursors are intermediates of the described pathway. The mutation also deregulated the control of aspartate kinase activity, which is allosterically inhibited by an excess of two effectors: L-threonine and L-lysine (34). Inability to biosynthesise homoserine results in methionine and threonine insufficiency. Hence, these mutants require medium supplementation with homoserine or threonine together with methionine. Due to economic reasons, this is a significant disadvantage for most potential applications. Therefore, we tried to obtain spontaneous revertants which can synthesise homoserine.

As a result, seven clones were isolated: RW.A, RW.B, RW.C, RW.D, RW.E, RW.F and RW.G. To evaluate their ability to biosynthesise homoserine, the strains were cultivated for $24 \mathrm{~h}$ in the defined mineral medium A without homoserine or threonine and methionine. Then, biomass concentration was measured in each sample (Fig. 1). Surprisingly, all strains were able to grow, even ATCC 13287. Nevertheless, its biomass concentration was significantly lower $(0.59 \mathrm{~g} / \mathrm{L})$ than in strains RW.C and RW.E, which reached 2.46 and $2.31 \mathrm{~g} / \mathrm{L}$ respectively. This phenomenon may be owing to the spontaneous reversion of parental strain to the homoserine prototrophy. The estimated frequency of spontaneous mutations is $10^{-10}-10^{-9}$ on a pair of nucleotides, for the generation of bacteria (35). Therefore, it is not surprising that we obtained only seven strains with homoserine prototrophy. It is worth noting that the genetic traits of each bacterial culture are not homogenous. Thus, single bacterial cells may have slightly different metabolic characteristics.

The parent culture of ATCC 13287 undergoes spontaneous reversion from auxotrophic to prototrophic, capable of homoserine biosynthesis. Moreover, it is very likely that other unpredictable changes in their genome sequences occurred. Various mutations and reversions can result in slightly different metabolic abilities. Therefore, isolated spontaneous revertants were excellent material for further studies. To increase the chance for thermotolerant strain isolation, revertants RW.C and RW.E, which exhibited the highest growth, were chosen.

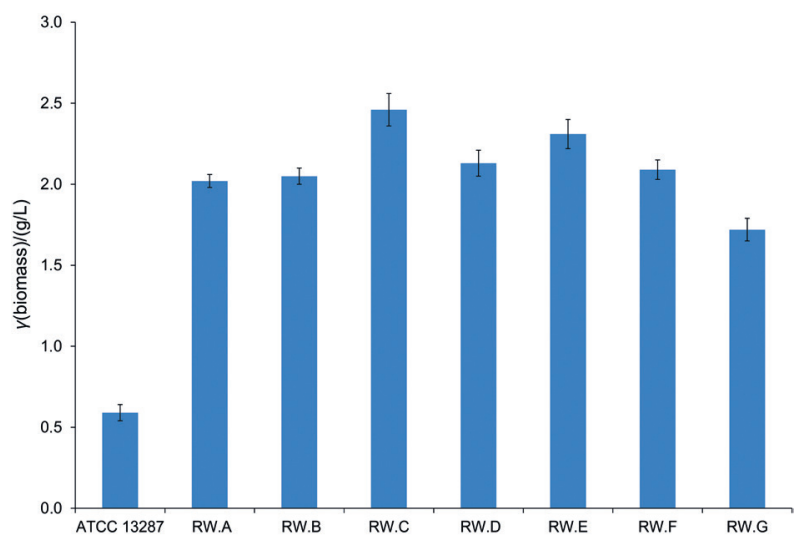

Fig. 1. Comparison of the biomass concentration after $24 \mathrm{~h}$ of cultivation in the mineral medium A without homoserine or threonine and methionine. ATCC 13287=auxotrophic mutant unable to biosynthesise homoserine; RW.A, RW.B, RW.C, RW.D, RW.E, RW.F, RW.G=revertants with homoserine prototrophy

\section{Isolation of thermotolerant strains on complex media}

In recent years, the spectrum of products possible to obtain with C. glutamicum has increased. In parallel, state of the art technologies using this microorganism have become not only more efficient but also cheaper. Searching for thermotolerant $C$. glutamicum strains able to grow at temperatures above $40^{\circ} \mathrm{C}$ is part of this trend. The use of such microorganisms significantly reduces the costs of cooling of the fermentation medium, which is very important, especially during summer time and in the tropical climate. It also reduces the risk of contamination by mesophilic microflora and allows conducting the simultaneous saccharification and fermentation of waste carbon sources. Optimal operating temperatures for enzymes used in these processes are usually above $40^{\circ} \mathrm{C}$. For this reason, production technologies using C. glutamicum have so far not been available (36-38).

Complex media are composed of extracts or hydrolysates prepared from yeast, beef, soy and plenty of other organic matter. They are sources of proteins and amino acids, and thus may play an important role in the protection of the cells against harsh environmental conditions, such as high temperature. Hence, using complex media, it is more feasible to select single bacterial cells capable of remaining metabolically active at the temperature much higher than previously described as maximum.

Parental strain ATCC 13287 and revertants RW.C and RW.E were used for selection of mutants able to grow in the complex medium at $44^{\circ} \mathrm{C}$. Suspensions of cells were plated directly on solid complex medium. It is known that already at $40^{\circ} \mathrm{C}$ the proliferation of $C$. glutamicum cells is significantly inhibited $(23,26)$. Surprisingly, after $24 \mathrm{~h}$ of incubation at $44^{\circ} \mathrm{C}$, single 

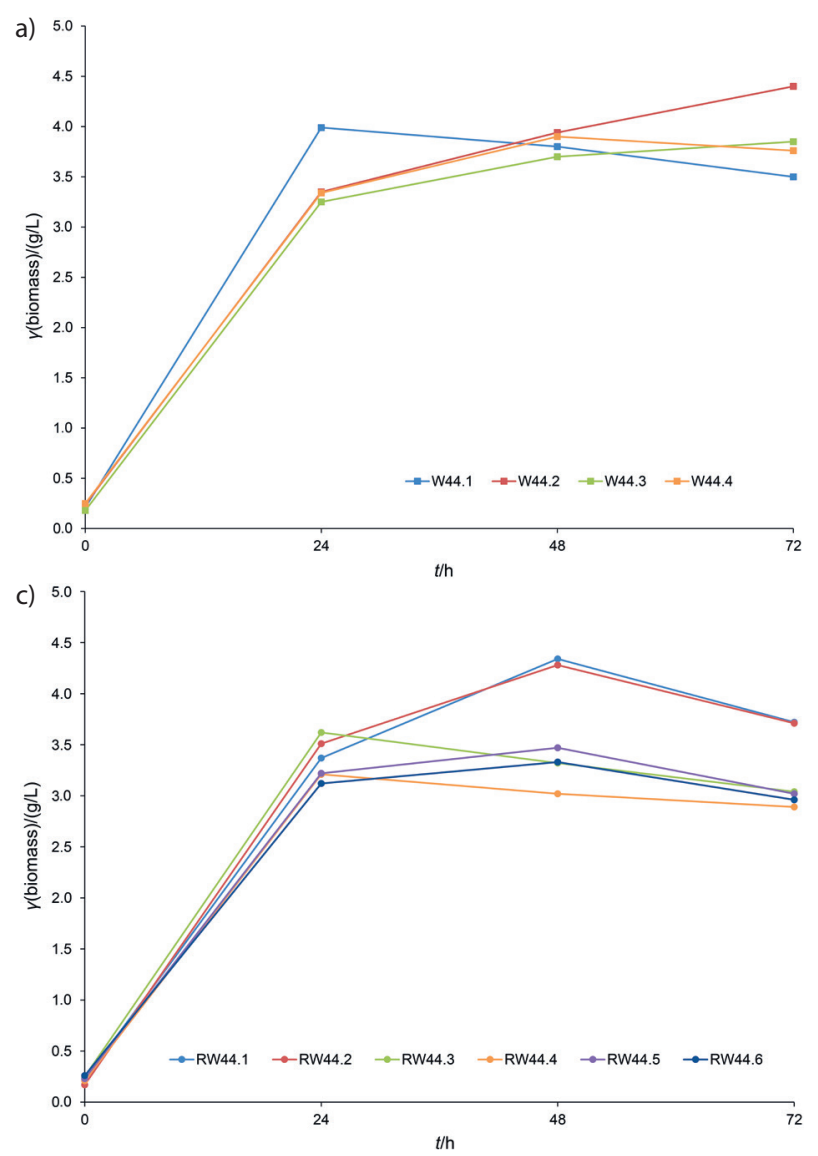
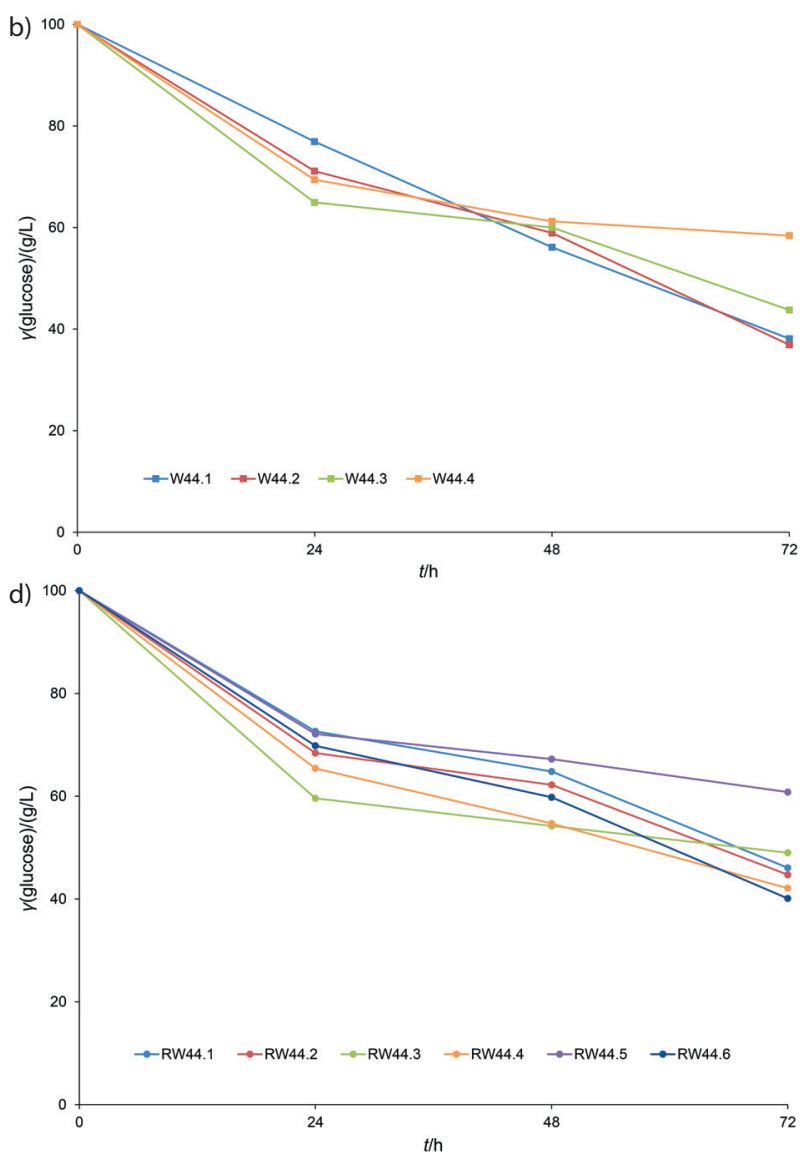

Fig. 2. Comparison of the biomass growth rate and consumption of glucose in the cultures of strains capable of growing at $44{ }^{\circ} \mathrm{C}$ : a) and b) auxotrophic strains (W44.1-W44.4), and c) and d) revertants with homoserine prototrophy (RW44.1-RW44.6)

colonies were formed - four ATCC 13287, four RW.E and two RW.C. The colonies of auxotrophic (W44.1, W44.2, W44.3 and W44.4) and prototrophic revertants (RW44.1, RW44.2, RW44.3, RW44.4, RW44.5, RW44.6, RW44.7 and RW44.8) were isolated and their ability to grow and utilise carbon source (Fig. 2) was tested.

As it was shown, there were no drastic differences in the growth and glucose consumption. However, only four strains, W44.1, W44.2, RW44.1 and RW44.2, achieved a biomass concentration of $4 \mathrm{~g} / \mathrm{L}$ or higher. The clones also exhibited sufficient metabolic activity, and after $72 \mathrm{~h}$ of incubation utilised about $62,63,54$ and $53 \mathrm{~g} / \mathrm{L}$ of glucose respectively. Hence, these strains were used in the next round of selection.

Complex culture media contain various substances which enable cells to outlast in hostile temperature conditions. Nonetheless, the expression of some genes may still be interrupted by the temperature factor. To obtain variants of the bacteria that exhibit higher metabolic activity at the temperature above $40^{\circ} \mathrm{C}$, their selection on media which include defined carbon source was carried out.

\section{Obtaining thermotolerant strains on mineral media}

To select the strains with higher metabolic activity at $44^{\circ} \mathrm{C}$, we used sodium succinate or citrate as a sole carbon source.
Both compounds are intermediates of the tricarboxylic acid cycle (TCA). Moreover, it is known that the expression of enzymes involved in their metabolism is strongly influenced by the temperature factor (21). Additionally, to complement TCA in supplementary carbon and nitrogen source, sodium glutamate was added.

Dense suspensions of the bacterial cells $\left(A_{540 \mathrm{~nm}} \approx 5\right)$ were seeded on mineral media with specified substrates as well as on control plates. After $24 \mathrm{~h}$ of incubation at $44^{\circ} \mathrm{C}$, the growth was not observed on negative control, the positive controls were densely covered with colonies (data not shown), while on media with citrate or succinate single colonies were formed (Fig. 3). Unexpectedly, the colonies varied in colour and size depending on the type of carbon source. The most interesting results were observed when the selection was performed on medium with citrate or citrate with glutamate (Fig. 3a; due to similar results, only one plate is shown). On a single plate, the colonies varied considerably. Their size was diverse and they were of different colours: creamy (WC44.4, WCG44.2, RC44.7, RCG44.6 and RCG44.7), yellow (WC44.3, RC44.5, RC44.6, RCG44.4 and RCG44.5) and deep orange (WC44.1, WC44.2, WCG44.1, WCG44.3, RC44.1, RC44.2, RC44.3, RC44.4, RCG44.1, RCG44.2, RCG44.3 and RCG44.8). In the presence of succinate colonies were creamy and small (Fig. 3 b). If the glutamate was added they were deep orange and much bigger (Fig. 3c). 


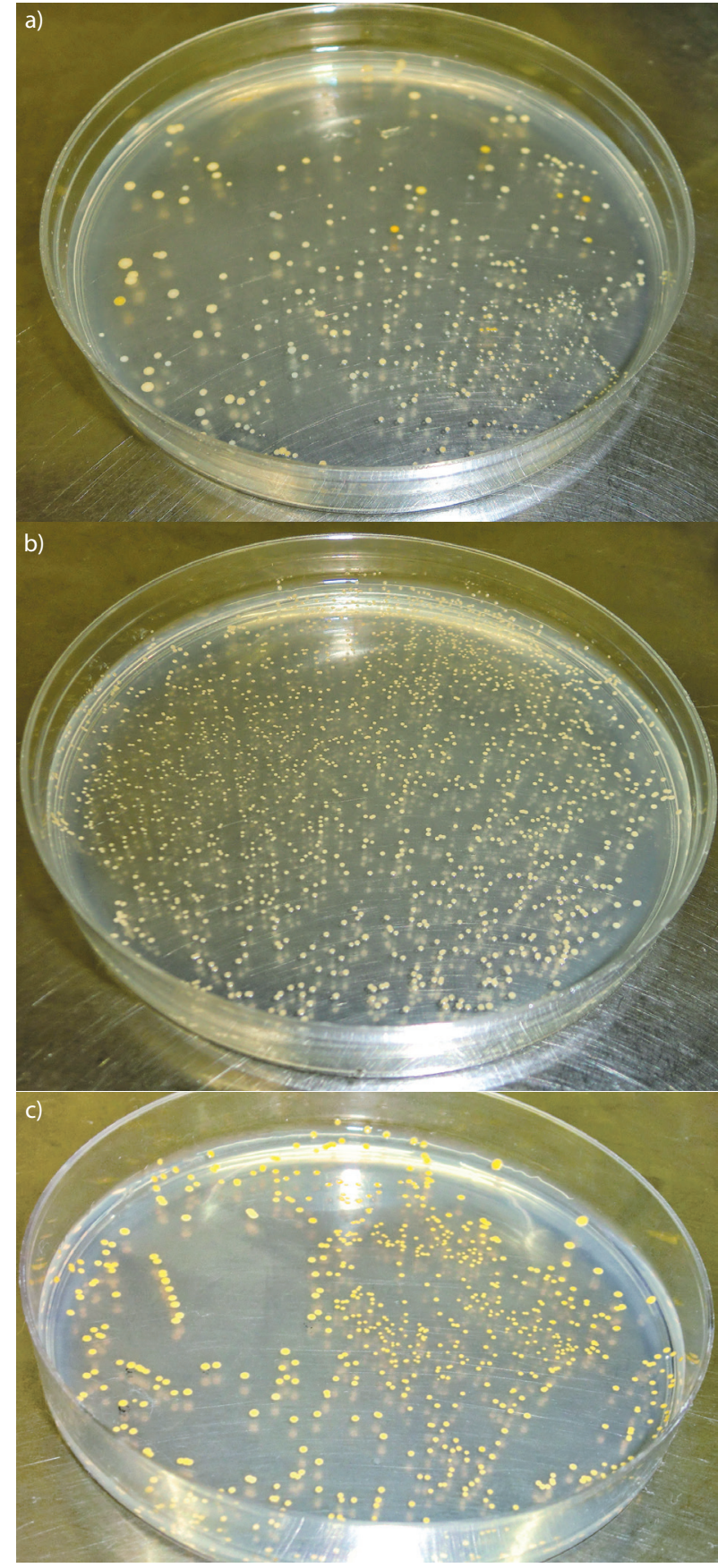

Fig. 3. Morphology of the colonies growing on various carbon sources: a) citrate or citrate with glutamate (due to similar results, only one plate is shown), b) succinate and c) succinate with glutamate

Some of the C. glutamicum strains (e.g. ATCC 13032) produce carotenoids (39). Their synthesis begins with the universal precursor formation: isopentenyl pyrophosphate and its isomer dimethylallyl pyrophosphate. They are derived from the methylerythritol phosphate pathway, which starts by condensation of pyruvate and glyceraldehyde 3-phosphate (39-43). During growth at the temperature above $40^{\circ} \mathrm{C}$, the pyruvate is accumulated in C. glutamicum cells and because it is toxic, it is converted into other less detrimental substances. The easiest way is to transform the pyruvate into lactic acid, which is easily secreted (22). The excess of pyruvate may also promote carotenoid formation. Therefore, strains growing as orange pigmented colonies on medium with citrate can exhibit high glycolytic activity and potentially the increased ability to biosynthesise L-lactic acid. The conducted selection could lead to a set of strains with different properties. To evaluate this hypothesis, from each medium overall 37 colonies were isolated and their growth and glucose consumption were tested at $40^{\circ} \mathrm{C}$.

An interesting phenomenon was observed for strains isolated from media containing citrate as well as citrate and glutamate. Although the selected microorganisms did not show prominent differences in growth, the glucose consumption was significantly more rapid (Fig. 4) in the cultures of C. glutamicum thermotolerant strains, growing as deep orange colonies, than creamy-coloured and yellow ones, which did not show any regularity in their response. It was striking that after the first $24 \mathrm{~h}$ of fermentation, all orange strains used $55 \%$ glucose, while others usually utilised about $41 \%$. Therefore, it can be concluded that the ability to form orange pigment is the indicator of increased metabolic activity.

For comparison, strains isolated from mineral media with succinate or succinate with glutamate reached a similar biomass concentration - about 3 g/L (Fig. $5 a$ and Fig. 5b). However, there was a possibility to isolate clones exhibiting significantly improved properties (Fig. $5 \mathrm{c}$ and Fig. $5 \mathrm{~d}$ ), such as WB44.3, WBG44.2 and RBG44.3. These strains had the highest glucose consumption. After the first 24 h, WB44.3 and WBG44.2 utilised 61 and $64 \%$ of glucose, respectively. Other strains were able to use it from $20 \%$ (RB44.3) to $55 \%$ (RBG44.5).

\section{Comparison of growth temperatures of strains at various stages}

To evaluate the effectiveness of the proposed selection method, the growth of nine strains: ATCC 13287, RW.C, W44.2, RW44.2, RCG44.3, RC44.4, WBG44.4, RB44.2 and RBG44.5 was measured at different temperatures (Fig. 6). Strains ATCC 13287 and RW.C were able to grow in the temperature range of $20-45^{\circ} \mathrm{C}$. However, the biomass concentration was the highest between $25-35^{\circ} \mathrm{C}$ with an optimum at $30^{\circ} \mathrm{C}$. The optimal growth temperature for strains isolated after incubation at $44{ }^{\circ} \mathrm{C}$ on the complex medium (W44.2 and RW44.2) was higher than for parental strain and revertant and reached $35^{\circ} \mathrm{C}$, but equally good conditions for cell proliferation were also at $40^{\circ} \mathrm{C}$. Strains RCG44.3, RC44.4, WBG44.4, RB44.2 and RBG44.5, which had been isolated from the mineral media, after incubation at $44^{\circ} \mathrm{C}$, were capable of growing in the temperature range of $25-45^{\circ} \mathrm{C}$. Estimated optimal growth temperature, in most cases, was the highest and reached $40{ }^{\circ} \mathrm{C}$.

Noteworthy are properties of strain RCG44.3. It grew well in the temperature range of $35-45^{\circ} \mathrm{C}$, with the final biomass concentration greater than $3 \mathrm{~g} / \mathrm{L}$ of dry cell mass. Its optimal growth temperature is significantly higher than of the parental strain, C. glutamicum ATCC 13287. Presented results confirm that selected strains exhibit increased tolerance of the temperature above $40^{\circ} \mathrm{C}$. 

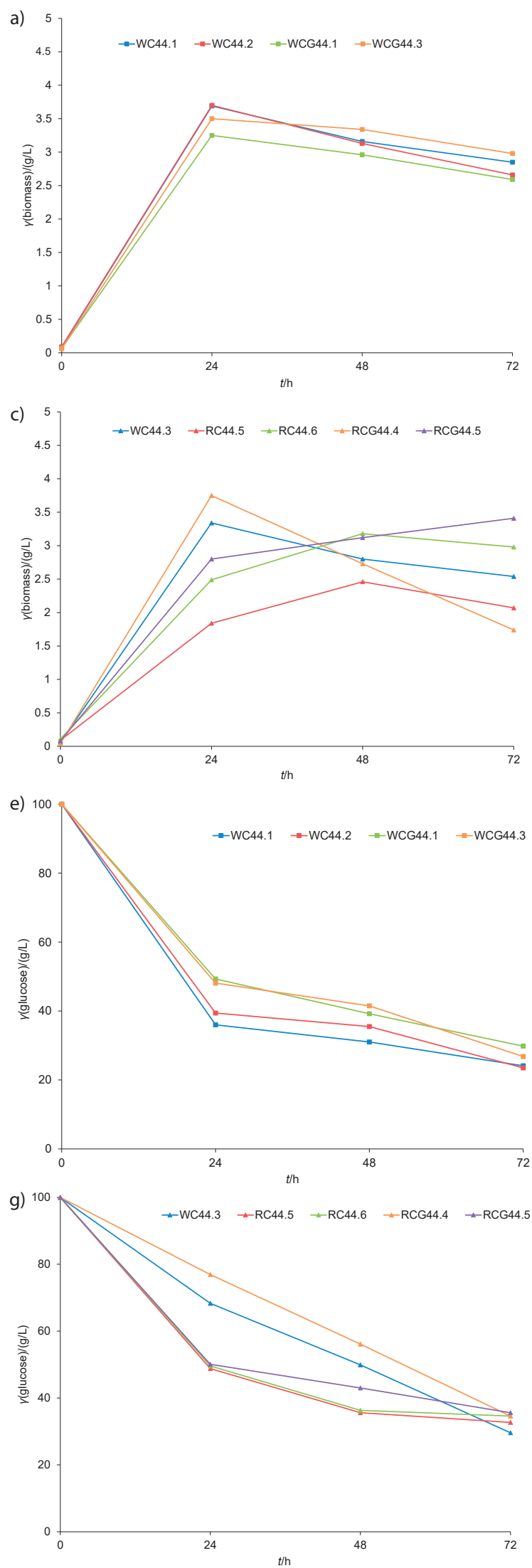
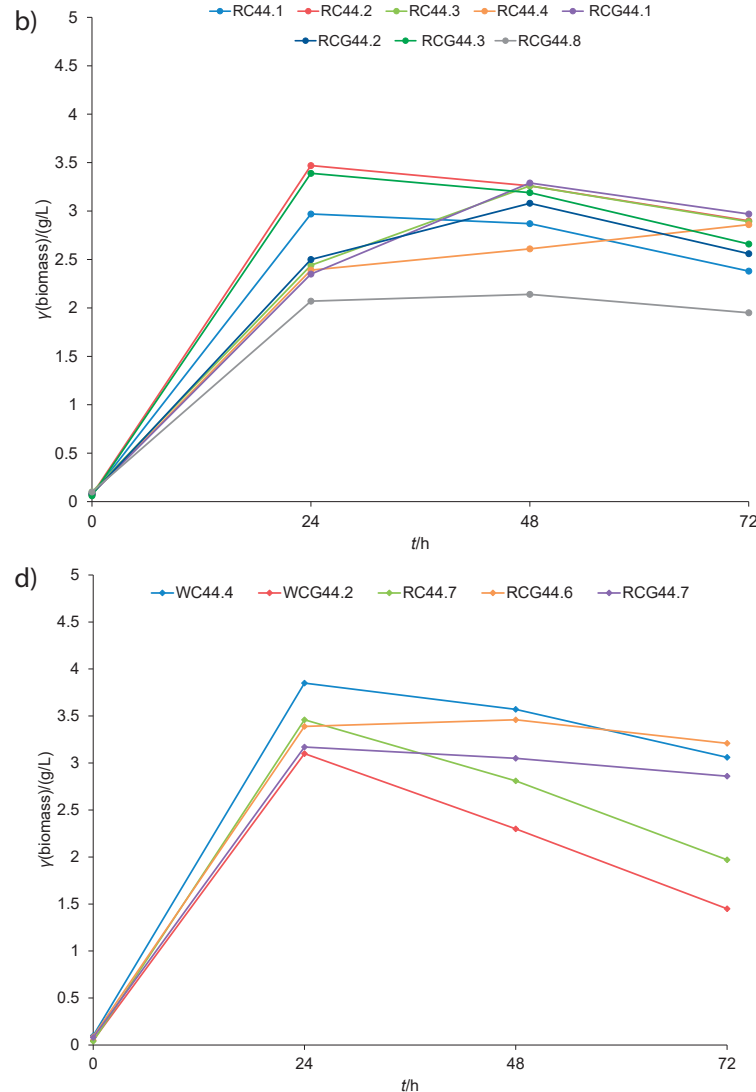

f) $\rightarrow$-RC44.1 $\rightarrow-R C 44.2 \rightarrow-R C 44.3 \rightarrow-R C 44.4 \rightarrow$ RCG44.1 $\rightarrow$ RCG44.2 $\rightarrow$ RCG44.3 $\rightarrow$ RCG44.8
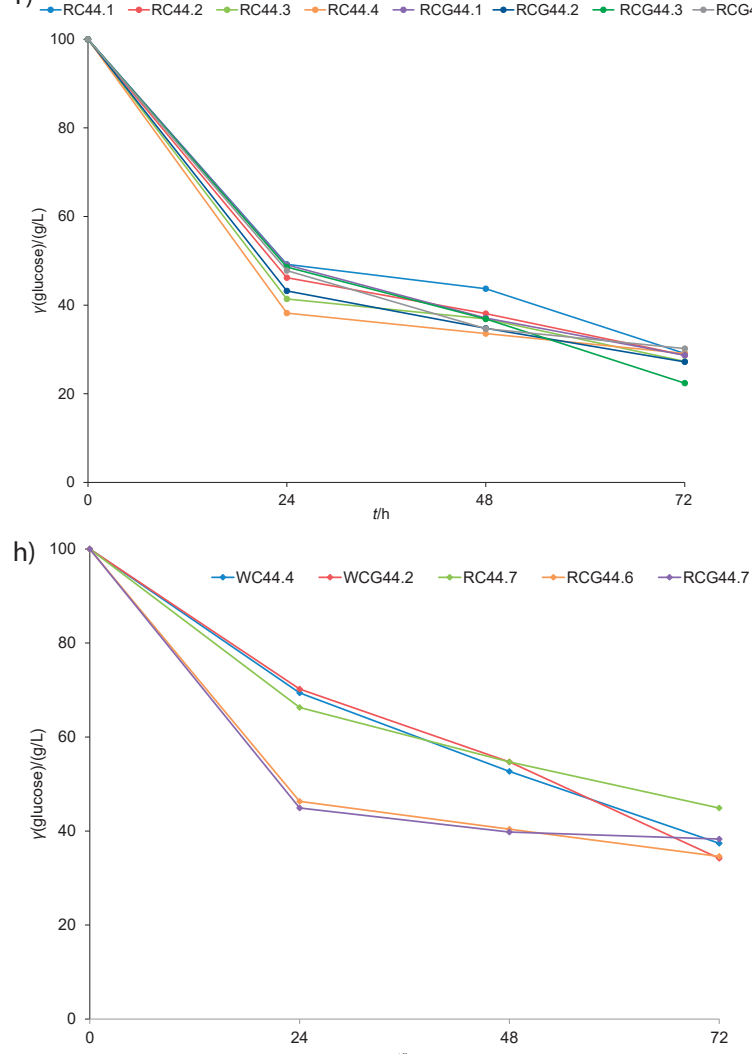

Fig. 4. Biomass concentration of the cultures of the strains grown at $44^{\circ} \mathrm{C}$, isolated from mineral medium containing citrate (WC.44 and RC.44) or citrate with glutamate (WCG.44 and RCG.44) as a sole carbon source: $a$ and b) orange colonies, c) yellow colonies, d) creamy colonies and e-h) their respective glucose consumption. WC.44 and WCG.44=homoserine auxotrophic mutants, RC.44 and RCG.44=revertants with homoserine prototrophy 
a)
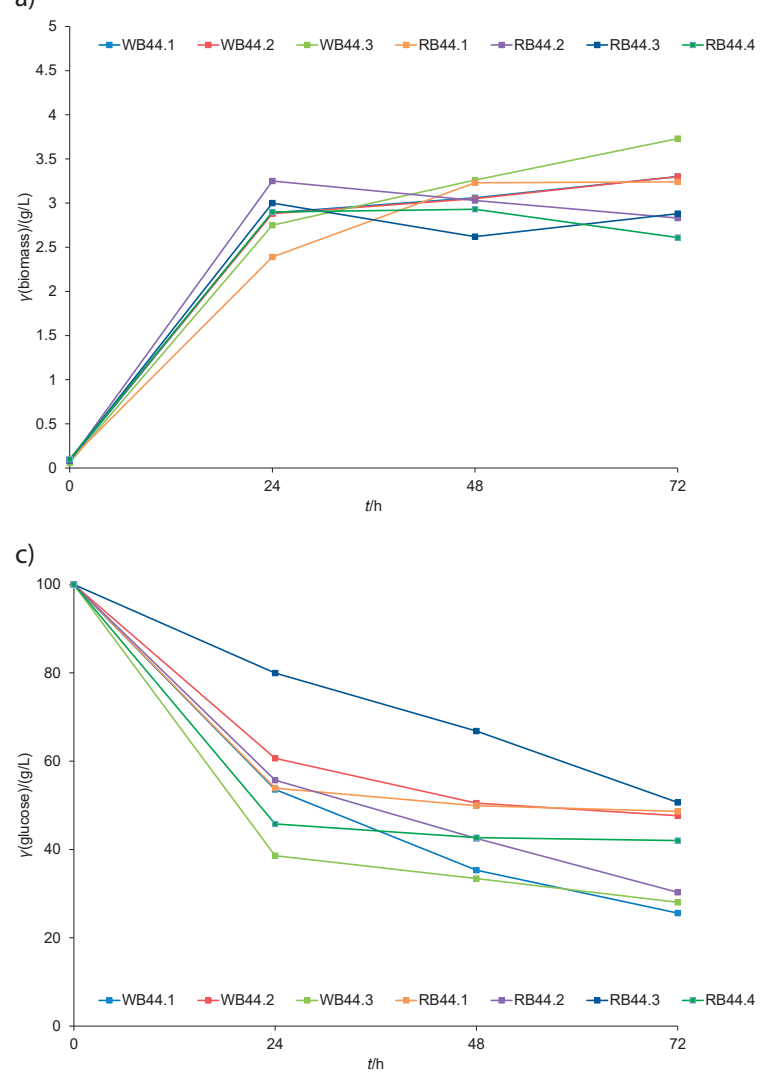
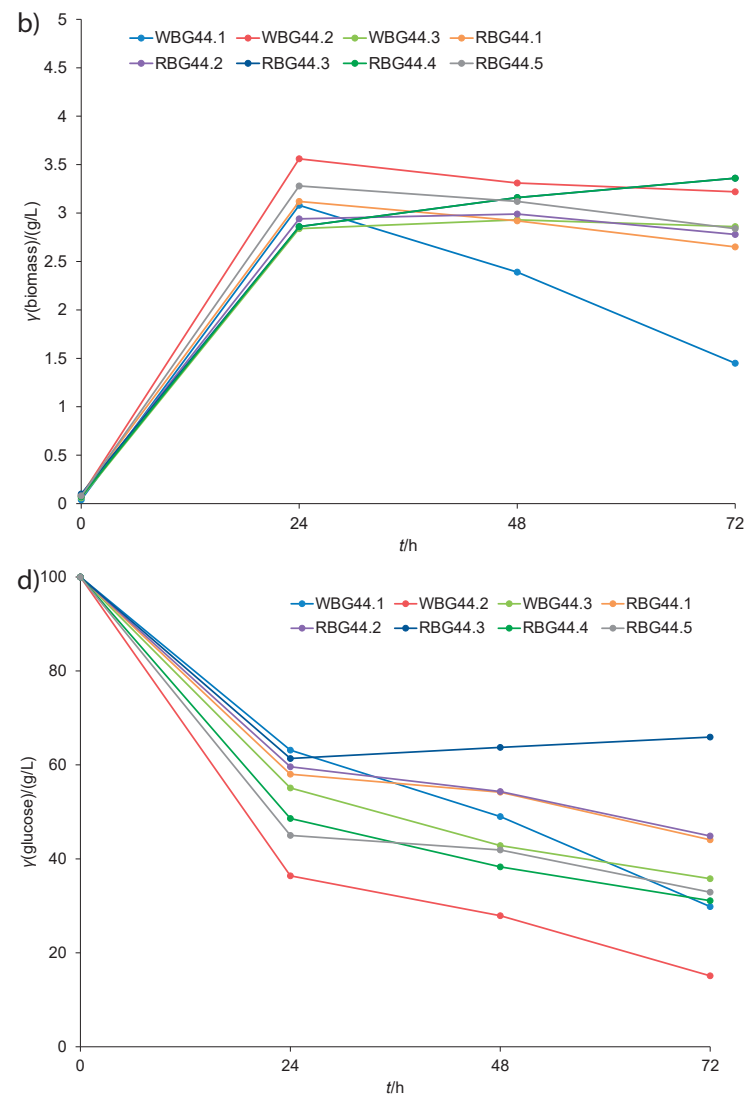

Fig. 5. Biomass concentration in cultures of the strains grown at $44{ }^{\circ} \mathrm{C}$ isolated from the mineral medium containing: a) succinate or b) succinate with glutamate, and $c$ and d) their respective glucose consumption. WB.44 and WBG.44=homoserine auxotrophic mutants, RB.44 and RBG.44=revertants with homoserine prototrophy

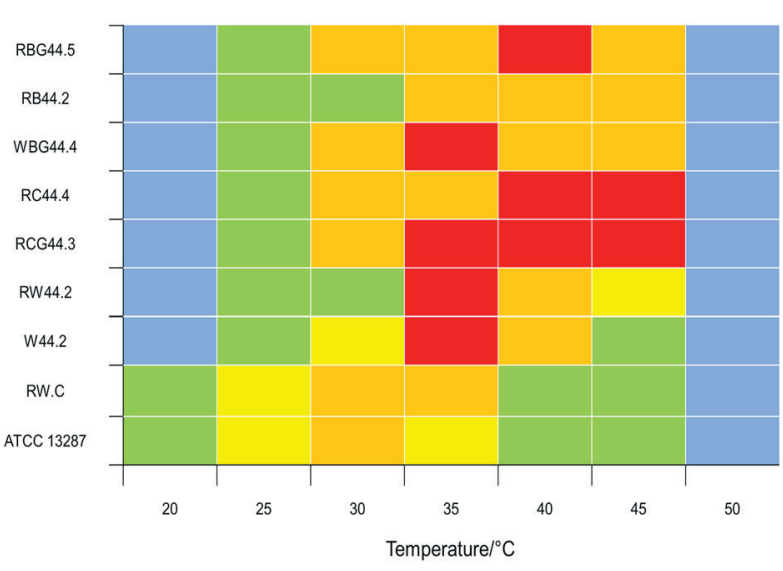

Fig. 6. Comparison of biomass concentration ( $\mathrm{g} / \mathrm{L}$ ) at different temperatures of strains isolated at diverse stages of selection; red=more than 3 , orange $=2-3$, yellow $=1-2$, green=less than 1 , blue $=$ no growth

\section{Organic acid production under oxygen-limiting conditions by strains isolated at various growth stages}

The organic acid biosynthesis by C. glutamicum is usually carried out under oxygen deprivation conditions, which inhibit the bacterial growth. Therefore, the carbon source can be more efficiently converted to organic acids. Moreover, it can be carried out in mineral media, without the addition of nitrogen sources, affecting the costs associated with the production and purification of organic acids (3,32,44-47). However, the simultaneous influence of both factors, limitation of aeration and elevated temperature, on the biosynthesis of organic acids by C. glutamicum has not been described so far.

As it was mentioned, the temperature affects the expression of genes involved, among others, in central metabolism. For this reason, changes in the organic acid production rate can be observed. The ability to biosynthesise lactic, succinic and acetic acids by selected strains: ATCC 13287, RW.C, W44.2, RW44.2, RCG44.3, RC44.4, WBG44.4, RB44.2 and RBG44.5 was evaluated (Table 1). After $24 \mathrm{~h}$ of incubation under oxygen limitation conditions, all of them produced mainly lactic acid. Its concentration depended on the strain, but was considerably higher in the cultures of RCG44.3, RC44.4, WBG44.4, RB44.2 and RBG44.5, reaching 27.1, 24.2, 20.2, 22.1 and $23.8 \mathrm{~g} / \mathrm{L}$ respectively, than in ATCC 13287 and RW.C, which produced about $15 \mathrm{~g} / \mathrm{L}$. It should also be emphasized that all of the $C$. glutamicum strains produced exclusively L-lactic acid (Table 1). Lactic acid productivity $\left(Q_{p}\right)$ was noticeably higher for strains capable of fermenting at $44{ }^{\circ} \mathrm{C}$. For instance, $Q_{p}$ for RW44.2, RCG44.3, RC44.4, WBG44.4, RB44.2 and RBG44.5 reached respectively $0.82,1.13,1.01,0.84,0.92$ and $0.99 \mathrm{~g} /(\mathrm{L} \cdot \mathrm{h})$, while for the parental strain ATCC 13287, it reached $0.62 \mathrm{~g} /(\mathrm{L} \cdot \mathrm{h})$. Also, the lactic acid yield $\left(Y_{\mathrm{PS}}\right)$ is affected by the temperature factor. 
Table 1. Concentration of glucose, lactic, succinic and acetic acids, production yield, productivity and concentration of lactic acid stereoisomers in the cultures of strains isolated at various growth stages

\begin{tabular}{|c|c|c|c|c|c|c|c|c|}
\hline \multirow{2}{*}{ Strain } & \multicolumn{4}{|c|}{$\gamma /(g / L)$} & \multirow{2}{*}{$Y_{\mathrm{pS}} /(\mathrm{g} / \mathrm{g})$} & \multirow{2}{*}{$Q_{p} /(g /(L \cdot h))$} & \multicolumn{2}{|c|}{$\gamma($ stereoisomer $) /(\mathrm{g} / \mathrm{L})$} \\
\hline & Glucose & Lactic & Succinic & Acetic & & & $\mathrm{L}$ & D \\
\hline ATCC 13287 & 63.8 & 14.8 & 3.20 & 0.31 & 0.41 & 0.62 & 16.4 & n.d. \\
\hline RW.C & 60.2 & 15.4 & 2.10 & 0.90 & 0.39 & 0.64 & 15.9 & n.d. \\
\hline W44.2 & 62.2 & 17.3 & 1.20 & 1.20 & 0.46 & 0.72 & 18.5 & n.d. \\
\hline RW44.2 & 57.1 & 19.6 & 0.80 & 1.42 & 0.46 & 0.82 & 19.7 & n.d. \\
\hline RCG44.3 & 52.2 & 27.1 & 0.60 & 3.24 & 0.57 & 1.13 & 29.2 & n.d. \\
\hline RC44.4 & 53.4 & 24.2 & 0.54 & 3.81 & 0.52 & 1.01 & 25.2 & n.d. \\
\hline WBG44.4 & 59.5 & 20.2 & 0.57 & 4.72 & 0.50 & 0.84 & $28 . .6$ & n.d. \\
\hline RB44.2 & 57.2 & 22.1 & 0.46 & 3.91 & 0.52 & 0.92 & 23.8 & n.d. \\
\hline RBG44.5 & 56.2 & 23.8 & 0.56 & 3.60 & 0.54 & 0.99 & 27.6 & n.d. \\
\hline
\end{tabular}

n.d=concentration lower than the detection limit $(\gamma=0.214 \mathrm{mg} / \mathrm{L})$

The thermotolerant strains isolated from mineral media with citrate or succinate as a sole carbon source convert more than half of the glucose to lactic acid. For comparison, in the cultures of strains growing at $30^{\circ} \mathrm{C}$ (ATCC 13287 and RW.C), the $Y_{\mathrm{PS}}$ value reached about $0.40 \mathrm{~g} / \mathrm{g}$. The influence of temperature is evident also in succinic and acetic acid biosynthesis. The highest concentration of succinate was observed in the culture of ATCC 13287, where it reached $3.20 \mathrm{~g} / \mathrm{L}$, while in the cultures of thermotolerant strains its amount did not exceed $1.20 \mathrm{~g} / \mathrm{L}$. The opposite tendency was observed for acetic acid formation. Its concentration increased significantly in the fermentation medium among thermotolerant strains. Parental strain ATCC 13287 produced $0.31 \mathrm{~g} / \mathrm{L}$ of acetate, while the thermotolerant strains isolated from mineral media with citrate or succinate as a sole carbon source synthesised at least ten times more of this metabolite.

The influence of elevated temperature on the biosynthesis of organic acids is unquestionable. The presented results confirmed previous observations published by Delaunay et al. (22), who described the influence of temperature on C. glutamicum 2262 metabolism. Increasing it from 33 to $39^{\circ} \mathrm{C}$, they observed a decrease in the biomass growth and increase in the concentration of lactic, succinic, acetic, pyruvic, citric and butyric acids, as well as in trehalose, a-ketoglutarate and dihydroxyacetone. Subsequent studies, carried out at $31-41^{\circ} \mathrm{C}$, confirmed these observations. Despite the aeration, the concentration of lactic acid reached $21.5 \mathrm{~g} / \mathrm{L}$ (23).

The thermotolerant strains of $C$. glutamicum can be an attractive solution in particular for the production of optically pure L-lactic acid. Thus far, only mesophilic strains have been used for this purpose. Khuat et al. (48) used mesophilic C. glutamicum 2264. In batch fermentation, the strain produced $27 \mathrm{~g} / \mathrm{L}$ of lactic acid, while in fed-batch fermentation its concentration reached $55.8 \mathrm{~g} / \mathrm{L}$, with productivity $\left(Q_{\mathrm{p}}\right)$ of 1.3 and $0.25 \mathrm{~g} /(\mathrm{L} \cdot \mathrm{h})$ respectively. C. glutamicum R produced $95 \mathrm{~g} / \mathrm{L}$ lactic acid in a two-stage batch fermentation, with high volumetric productivity of 15.8 $\mathrm{g} /(\mathrm{L} \cdot \mathrm{h})$; however, the biomass concentration was $60 \mathrm{~g} / \mathrm{L}$ (3). For D-lactic acid biosynthesis, a similar system was used. A genetically modified C. glutamicum $\Delta / d h A / p C R B 204$ produced D-lactic acid with high optical purity (>99.9\%), reaching the concentration of $120 \mathrm{~g} / \mathrm{L}$, and productivity of $4.0 \mathrm{~g} /(\mathrm{L} \cdot \mathrm{h})(4)$.
The thermotolerant strains of C. glutamicum are not a ready solution for the biosynthesis of lactic acid. However, the described studies clearly show their potential - cultivation at elevated temperature results in physiological changes that are beneficial for this process.

\section{CONCLUSIONS}

Using the described method of selection, we were able to obtain a collection of Corynebacterium glutamicum strains capable of tolerating high temperatures. They grew faster and produced more lactic acid at $44^{\circ} \mathrm{C}$ than parental strain. Particularly noteworthy is C. glutamicum RCG44.3. This strain had the optimal growth temperature in the range of $35-45^{\circ} \mathrm{C}$. Under oxygen deprivation conditions, it produced $27.1 \mathrm{~g} / \mathrm{L}$ lactic acid, $3.2 \mathrm{~g} / \mathrm{L}$ acetic acid and $0.6 \mathrm{~g} / \mathrm{L}$ succinic acid, with biomass concentration about $10 \mathrm{~g} / \mathrm{L}$. Although the final concentration of lactic acid is not satisfactory for industrial production, the presented method of selection gives the opportunity to obtain new, efficient strains, which can be used in the production of L-lactic acid in the entirely mineral medium.

\section{ORCID IDs}

M. Leszczewicz @ https://orcid.org/0000-0002-8474-7915 P. Walczak (1) https://orcid.org/0000-0003-1485-4878

\section{REFERENCES}

1. Kinoshita S, Nakayama K, Akita S. Taxonomical study of glutamic acid accumulating bacteria, Micrococcus glutamicus nov. sp. Bull Agr Chem Soc Japan. 1958;22(3):176-85. https://doi.org/10.1080/03758397.1958.10857463

2. Becker J, Wittmann C. Bio-based production of chemicals, materials and fuels - Corynebacterium glutamicum as versatile cell factory. Curr Opin Biotechnol. 2012;23(4):631-40. https://doi.org/10.1016/j.copbio.2011.11.012

3. Okino S, Inui M, Yukawa H. Production of organic acids by Corynebacterium glutamicum under oxygen deprivation. Appl Microbiol Biotechnol. 2005;68(4):475-80. https://doi.org/10.1007/s00253-005-1900-y 
4. Okino S, Suda M, Fujikura K, Inui M, Yukawa H. Production of D-lactic acid by Corynebacterium glutamicum under oxygen deprivation. Appl Microbiol Biotechnol. 2008;78(3):449-54. https://doi.org/10.1007/s00253-007-1336-7

5. Litsanov B, Brocker M, Bott M. Toward homosuccinate fermentation: Metabolic engineering of Corynebacterium glutamicum for anaerobic production of succinate from glucose and formate. Appl Environ Microbiol. 2012;78(9): 3325-37.

https://doi.org/10.1128/AEM.07790-11

6. Wieschalka S, Blombach B, Eikmanns BJ. Engineering Corynebacterium glutamicum for the production of pyruvate. Appl Microbiol Biotechnol. 2012;94(2):449-59.

https://doi.org/10.1007/s00253-011-3843-9

7. Jojima T, Noburyu R, Sasaki M, Tajima T, Suda M, Yukawa $\mathrm{H}$, Inui M. Metabolic engineering for improved production of ethanol by Corynebacterium glutamicum. Appl Microbiol Biotechnol. 2015;99(3):1165-72.

https://doi.org/10.1007/s00253-014-6223-4

8. Smith KM, Cho KM, Liao JC. Engineering Corynebacterium glutamicum for isobutanol production. Appl Microbiol Biotechnol. 2010;87(3):1045-55.

https://doi.org/10.1007/s00253-010-2522-6

9. Schneider J, Wendisch VF. Putrescine production by engineered Corynebacterium glutamicum. Appl Microbiol Biotechnol. 2010;88(4):859-68.

https://doi.org/10.1007/s00253-010-2778-x

10. Mimitsuka T, Sawai H, Hatsu M, Yamada K. Metabolic engineering of Corynebacterium glutamicum for cadaverine fermentation. Biosci Biotechnol Biochem. 2007;71(9):2130-5. https://doi.org/10.1271/bbb.60699

11. Choi JW, Yim SS, Lee SH, Kang TJ, Park SJ, Jeong KJ. Enhanced production of gamma-aminobutyrate (GABA) in recombinant Corynebacterium glutamicum by expressing glutamate decarboxylase active in expanded $\mathrm{pH}$ range. Microb Cell Fact. 2015;14:21.

https://doi.org/10.1186/s12934-015-0205-9

12. Sasaki M, Jojima T, Inui M, Yukawa H. Xylitol production by recombinant Corynebacterium glutamicum under oxygen deprivation. Appl Microbiol Biotechnol. 2010;86(4):1057-66. https://doi.org/10.1007/s00253-009-2372-2

13. Jo SJ, Maeda M, Ooi T, Taguchi S. Production system for biodegradable polyester polyhydroxybutyrate by Corynebacterium glutamicum. J Biosci Bioeng. 2006;102(3):233-6. https://doi.org/10.1263/jbb.102.233

14. Yu X, Jin H, Liu W, Wang Q, Qi Q. Engineering Corynebacterium glutamicum to produce 5 -aminolevulinic acid from glucose. Microb Cell Fact. 2015;14:183.

https://doi.org/10.1186/s12934-015-0364-8

15. Castillo Martinez FA, Balciunas EM, Salgado JM, Domínguez González JM, Converti A, de Souza Oliveira RP. Lactic acid properties, applications and production: A review. Trends
Food Sci Technol. 2013;30(1):70-83.

https://doi.org/10.1016/j.tifs.2012.11.007

16. Ghaffar T, Irshad M, Anwar Z, Aqil T, Zulifqar Z, Tariq A, et al. Recent trends in lactic acid biotechnology: A brief review on production to purification. J Radiat Res Appl Sci. 2013; 7(2):222-9.

https://doi.org/10.1016/j.jrras.2014.03.002

17. Chen X, Jiang S, Li X, Pan L, Zheng Z, Luo S. Production of succinic acid and lactic acid by Corynebacterium crenatum under anaerobic conditions. Ann Microbiol. 2012;63(1):39-44. https://doi.org/10.1007/s13213-012-0441-8

18. Okano K, Tanaka T, Ogino C, Fukada H, Kondo A. Biotechnological production of enantiomeric pure lactic acid from renewable resources: Recent achievements, perspectives, and limits. Appl Microbiol Biotechnol. 2010;85(3):413-23. https://doi.org/10.1007/s00253-009-2280-5

19. Jia X, Liu P, Li S, Li S, Wen J. D-lactic acid production by a genetically engineered strain Corynebacterium glutamicum. World J Microbiol Biotechnol. 2011;27(9):2117-24.

https://doi.org/10.1007/s11274-011-0675-9

20. Abe S, Takayama KI, Kinoshita S. Taxonomical studies on glutamic acid-producing bacteria. J Gen Appl Microbiol. 1967;13(3):279-301.

https://doi.org/10.2323/jgam.13.279

21. Ohnishi J, Hayashi M, Mitsuhashi S, Ikeda M. Efficient $40^{\circ} \mathrm{C}$ fermentation of L-lysine by a new Corynebacterium glutamicum mutant developed by genome breeding. Appl Microbiol Biotechnol. 2003;62(1):69-75.

https://doi.org/10.1007/s00253-003-1254-2

22. Delaunay S, Gourdon P, Lapujade P, Mailly E, Oriol E, Engasser JM, et al. An improved temperature-triggered process for glutamate production with Corynebacterium glutamicum. Enzyme Microb Technol.1999;25(8-9):762-8. https://doi.org/10.1016/S0141-0229(99)00120-9

23. Delaunay S, Lapujade P, Engasser JM, Goergen JL. Flexibility of the metabolism of Corynebacterium glutamicum 2262, a glutamic acid-producing bacterium, in response to temperature upshocks. J Ind Microbiol Biotechnol. 2002;28(6):333-7. https://doi.org/10.1038/sj/jim/7000251

24. Momose H, Takagi T. Glutamic acid production in biotin-rich media by temperature-sensitive mutants of Brevibacterium lactofermentum, a novel fermentation process. Agric Biol Chem. 1978;42(10):1911-7.

https://doi.org/10.1080/00021369.1978.10863274

25. Lapujade P, Goergen JL, Engasser JM. Glutamate excretion as a major kinetic bottleneck for the thermally triggered production of glutamic acid by Corynebacterium glutamicum. Metab Eng. 1999;1(3):255-61.

https://doi.org/10.1006/mben.1999.0129

26. Gourdon P, Lindley ND. Metabolic analysis of glutamate production by Corynebacterium glutamicum. Metab Eng. 1999;1(3):224-31.

https://doi.org/10.1006/mben.1999.0122 
27. Kirchner O, Tauch A. Tools for genetic engineering in the amino acid-producing bacterium Corynebacterium glutamicum. J Biotechnol. 2003;104(1-3):287-99.

https://doi.org/10.1016/S0168-1656(03)00148-2

28. Nešvera J, Pátek M. Tools for genetic manipulations in Corynebacterium glutamicum and their applications. Appl Microbiol Biotechnol. 2011;90(5):1641-54. https://doi.org/10.1007/s00253-011-3272-9

29. Zheng P, Liu M, Liu XD, Du QY, Ni Y, Sun ZH. Genome shuffling improves thermotolerance and glutamic acid production of Corynebacteria glutamicum. World J Microbiol Biotechnol. 2012;28(3):1035-43.

https://doi.org/10.1007/s11274-011-0902-4

30. Drake JW. A constant rate of spontaneous mutation in DNA-based microbes. Proc Natl Acad Sci USA. 1991;88(16):7160-4. https://doi.org/10.1073/pnas.88.16.7160

31. Lee JY, Seo J, Kim ES, Lee HS, Kim P. Adaptive evolution of Corynebacterium glutamicum resistant to oxidative stress and its global gene expression profiling. Biotechnol Lett. 2013;35(5):709-17. https://doi.org/10.1007/s10529-012-1135-9

32. Oide S, Gunji W, Moteki Y, Yamamoto S, Suda M, Jojima T, et al. Thermal and solvent stress cross-tolerance conferred to Corynebacterium glutamicum by adaptive laboratory evolution. Appl Environ Microbiol. 2015;81(7):2284-98. https://doi.org/10.1128/AEM.03973-14

33. Microsoft Excel, v. 2007 professional, Microsoft Corp., Redmond, WA, USA; 2007.

34. Shukuo K, Kiyoshi N, Sohei K. Method of producing L-lysine by fermentation. US patent US2979439A. 1961.

35. Schroeder JW, Yeesin P, Simmons LA, Wang JD. Sources of spontaneous mutagenesis in bacteria. Crit Rev Biochem Mol Biol. 2018;53(1):29-48.

https://doi.org/10.1080/10409238.2017.1394262

36. Ou MS, Ingram LO, Shanmugam KT. L(+)-Lactic acid production from non-food carbohydrates by thermotolerant Bacillus coagulans. J Ind Microbiol Biotechnol. 2011;38(5):599-605. https://doi.org/10.1007/s10295-010-0796-4

37. van der Pol EC, Eggink G, Weusthuis RA. Production of $\mathrm{L}(+)$-lactic acid from acid pretreated sugarcane bagasse using Bacillus coagulans DSM2314 in a simultaneous saccharification and fermentation strategy. Biotechnol Biofuels. 2016;9:248.

https://doi.org/10.1186/s13068-016-0646-3

38. Kong X, Zhang B, Hua Y, Zhu Y, Li W, Wang D, Hong J. Efficient L-lactic acid production from corncob residue using metabolically engineered thermo-tolerant yeast. Bioresour Technol. 2019;273:220-30.

https://doi.org/10.1016/j.biortech.2018.11.018

39. Eggeling $L$, Bott $M$, editors. Handbook of Corynebacterium glutamicum. Boca Raton, FL, USA: CRC Press; 2005.
40. Heider SAE, Peters-Wendisch P, Wendisch VF. Carotenoid biosynthesis and overproduction in Corynebacterium glutamicum. BMC Microbiol. 2012;12:198.

https://doi.org/10.1186/1471-2180-12-198

41. Heider SAE, Wolf N, Hofemeier A, Peters-Wendisch P, Wendisch VF. Optimization of the IPP precursor supply for the production of lycopene, decaprenoxanthin and astaxanthin by Corynebacterium glutamicum. Front Bioeng Biotechnol. 2014;2:Article No. 28.

https://doi.org/10.3389/fbioe.2014.00028

42. Heider SAE, Peters-Wendisch P, Netzer R, Stafnes M, Brautaset $T$, Wendisch VF. Production and glucosylation of $C 50$ and C40 carotenoids by metabolically engineered Corynebacterium glutamicum. Appl Microbiol Biotechnol. 2014;98(3): 1223-35.

https://doi.org/10.1007/s00253-013-5359-y

43. Krubasik P, Takaichi S, Maoka T, Kobayashi M, Masamoto K, Sandmann G. Detailed biosynthetic pathway to decaprenoxanthin diglucoside in Corynebacterium glutamicum and identification of novel intermediates. Arch Microbiol. 2001;176(3):217-23.

https://doi.org/10.1007/s002030100315

44. Inui M, Murakami S, Okino S, Kawaguchi H, Vertès AA, Yukawa $\mathrm{H}$. Metabolic analysis of Corynebacterium glutamicum during lactate and succinate productions under oxygen deprivation conditions. J Mol Microbiol Biotechnol. 2004; 7(4):182-96.

https://doi.org/10.1159/000079827

45. Inui $M$, Suda $M$, Okino $S$, Nonaka $H$, Puskás LG, Vertès AA, Yukawa $\mathrm{H}$. Transcriptional profiling of Corynebacterium glutamicum metabolism during organic acid production under oxygen deprivation conditions. Microbiology. 2007; 153(8):2491-504.

https://doi.org/10.1099/mic.0.2006/005587-0

46. Wieschalka S, Blombach B, Bott M, Eikmanns BJ. Bio-based production of organic acids with Corynebacterium glutamicum. Microb Biotechnol. 2013;6(2):87-102. https://doi.org/10.1111/1751-7915.12013

47. Dominguez H, Nezondet C, Lindley ND, Cocaign M. Modified carbon flux during oxygen limited growth of Corynebacterium glutumicum and the consequences for amino acid overproduction. Biotechnol Lett.1993;15(5):449-54.

https://doi.org/10.1007/BF00129316

48. Khuat HBT, Kaboré AK, Olmos E, Fick M, Boudrant J, Goergen $\mathrm{J}$, et al. Lactate production as representative of the fermentation potential of Corynebacterium glutamicum 2262 in a one-step process. Biosci Biotechnol Biochem. 2014;78(2): 343-9.

https://doi.org/10.1080/09168451.2014.878219 